\title{
URBAN CYCLING AS AN INDICATOR OF SOCIO-ECONOMIC INNOVATION AND SUSTAINABLE TRANSPORT
}

\author{
Michą AdAm KWiatKOWSKI \\ Department of Urban and Regional Development Studies, Faculty of Earth Sciences, \\ Nicolaus Copernicus University in Torun \\ Manuscript received: September 26, 2018 \\ Revised version: November 5, 2018
}

\begin{abstract}
KWIATKOWSKI M.A., 2018. Urban cycling as an indicator of socio-economic innovation and sustainable transport. Quaestiones Geographicae 37(4), Bogucki Wydawnictwo Naukowe, Poznań, pp. 23-32. 1 fig.

ABSTRACT: Environmental pollution in cities is an increasingly popular issue tackled in research. One of the elements with a significant impact on the state of urban ecosystems is transport with its pressure on individual components of the environment. Sustainable urban transport is gaining prominence as a postulate expressed in cities' strategic documents, constituting an element alleviating the negative effects of anthropopressure. In the light of the need to introduce innovative solutions for clean forms of transport, numerous papers indicate the bicycle as an answer to some of those problems. The article presents a review of literature referring to the socio-economic aspects of using the bicycle in cities as a means of transport for daily commuting. The analysis is based on publications on cyclist safety in road traffic, the perception of the bicycle as a means of transport in cities, and the introduction of innovative solutions, such as bicycle-sharing systems.
\end{abstract}

KEY WORDS: bicycle, sustainable urban transport, cycling safety, bicycle paths, bicycle-sharing system, literature review Corresponding author: Michat Adam Kwiatkowski, Department of Urban and Regional Development Studies, Faculty of Earth Sciences, Nicolaus Copernicus University in Toruń, ul. Gagarina 11, 87-100 Toruń, Poland, e-mail:kwiat@doktorant.umk.pl

\section{Introduction}

Movement in urban space is one of numerous challenges of the modern world. Problems with transport result from both endogenous and exogenous functions performed by cities, which has a critical impact on the number of people interested in commuting and the need to meet their transport requirements. The quality of public transport translates largely to the life quality of its inhabitants, both in economic and environmental terms. Congestion in cities contributes not only to losses in the economic dimension through systematic disruption of transport fluidity, but also to an increase in pollution levels in cities (Bharadwaj et al. 2017). Trying to respond to the problem, agglomerations are seeking an alternative for the currently used forms of urban transport by implementing solutions inscribed in the concept of sustainable urban transport that pays particular attention to means of transport with the weakest possible environmental pressure. In this scope, cities' spatial policies are increasingly concentrating on cyclists as road users in urban transport.

The paper aims to give a review of the literature referring to the social and economic aspects of cycling development in cities. It analyses issues regarding cycling safety in road traffic, the perception of the bicycle as an alternative means of urban transport, and bicycle-sharing systems as innovations in urban public transport. 


\section{Selected socio-economic aspects of cycling in urban transport}

The bicycle, as an emission-free means of transport bringing numerous environmental benefits to the city, meets all the requirements of the idea of sustainable urban transport (Jennings 2015). It is promoted through the growing accessibility of bicycle paths and lanes in the city transport network, and the establishment of public bicycle rental systems which supplement the urban system of the means of transport (Zawieska, Pieriegud 2018). Daily cycle commuting is also highly beneficial for the health of city residents and the natural environment in cities because it contributes to a decrease in the number of cars emitting combustion gases. Moreover, cycling has a positive impact on human health and physical activity (Oja et al. 1998). An increase in available cycling infrastructure is conducive to the popularisation of this form of activity, contributing to improved health and well-being of city residents (Schepers et al. 2015). The inhabitants also reap financial benefits from cycling in the city because the cost of travel by bicycle is considerably lower than the cost incurred when driving a car over the same distance (Gössling, Hoi 2015).
Since the issues related to cycling in urban transport are so diverse, they are becoming more and more commonly researched by representatives of a wide range of fields of study. The topic of cycling in cities is discussed in numerous publications within geographic, social, economic, and public health sciences. This highlights the multifaceted nature of the topic. Publications regarding the socio-economic aspects of cycling in the city may be divided into several research trends encompassing individual directions of study (Fig. 1). The core trends include: the perception of the bicycle as a means of urban transport, cycling safety in cities, and the bicycle-sharing system as an innovation in the urban transport system. The proposed directions of study related to the perception of the bicycle as an everyday means of transport in the city refer to the factors stimulating the use of bicycles in urban transport, the relationship between the perception of the bicycle as a means of transport and socio-demographic features, the activity of bicycle associations and non-governmental organisations, as well as the cycling policies of cities. Research on safety comprises publications regarding the interaction of cyclists and other road users and the resulting potential conflicts, the relationship between the number of accidents and the state

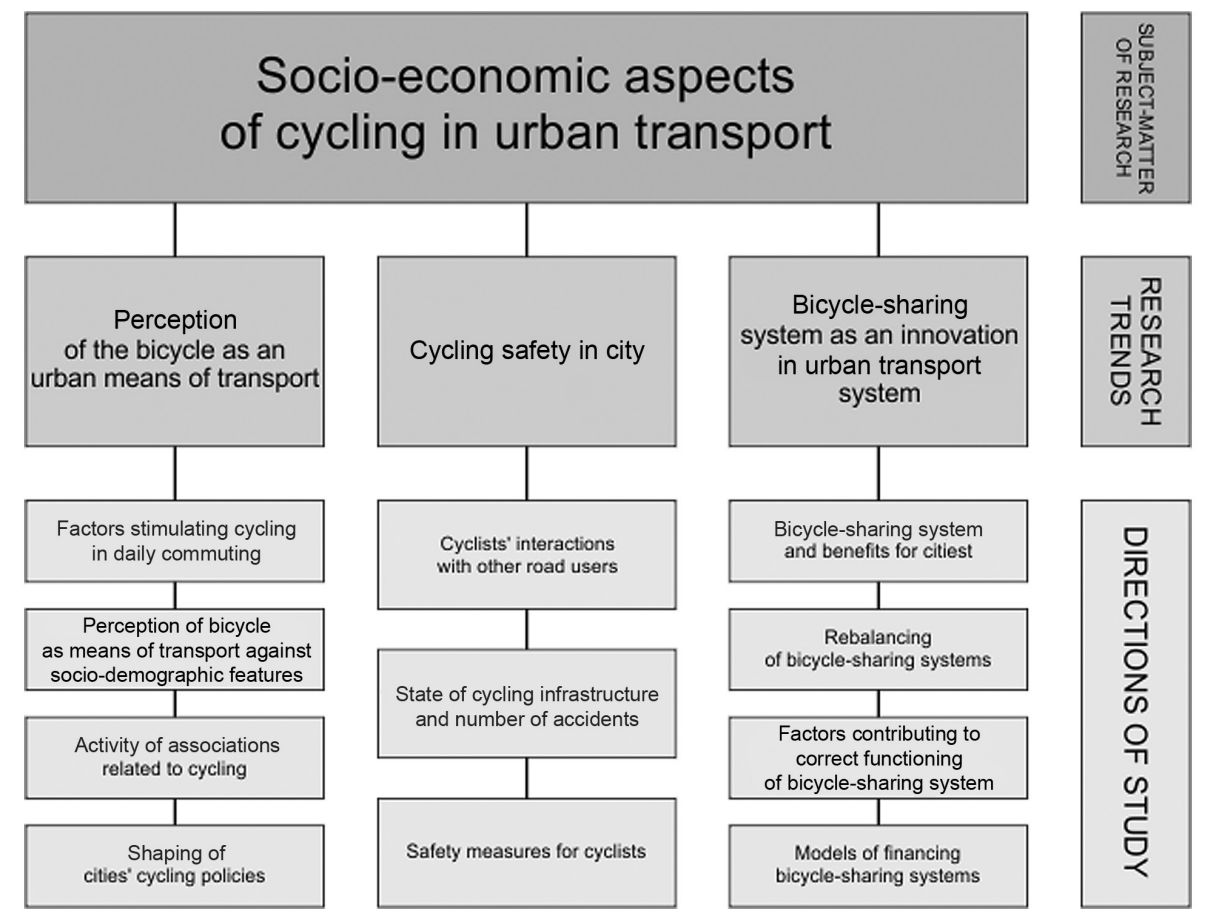

Fig. 1. Research trends and directions regarding the socio-economic aspects of cycling in urban transport. Source: author's own work on the basis of a literature query. 
of infrastructure and cyclist behaviour, and factors determining the use of safety measures (e.g. helmets). The trend related to the bicycle-sharing system is divided into directions of study regarding the benefits of such systems in cities, research on the rebalancing problem, factors contributing to the success of the systems, as well as their financing models (Fig. 1).

In the light of the literature query, three research trends may be distinguished, each consisting of several more detailed directions of study. The presented diagram does not exhaust the topic of socio-economic aspects of cycling in urban transport. The division is a proposed classification of the analysed publications related to the subject-matter of research and may be modified as further literature studies are conducted and new research problems arise.

\section{Perception of the bicycle as an urban means of transport}

The analysis of the socio-economic aspects of cycling in urban transport involves numerous studies describing the motivations for using the bicycle in daily commuting. This research trend contains a number of publications presenting the results of studies referring to the behaviour of bicycle path users as depending on socio-demographic features, but also on the activity of social movements and non-governmental organisations focusing on improving the quality of bicycle transport in cities and shaping cities' cycling policies.

On their introduction, bicycles were seen as recreational gear for the better-off part of society. Only after a certain period did the working class make them into a means of transport used to commute to work (Rodrigue et al. 2013). Nowadays, there is an ample body of research on the social perception of the bicycle as a means of transport, especially in daily commuting. One of the directions of study in this trend deals with factors that persuade residents to use the bicycle in urban transport. In the conducted research it was determined that the state of the cycling infrastructure has a far-reaching impact on the choice of the bicycle as a means of commuting to work (Gatersleben, Appleton 2007). Of particular importance is the manner in which bicycle paths are organised - they ought to be constructionally separated from pedestrian traffic (Wardman et al. 2007), especially in central parts of cities (Heesch et al. 2015). The increased number of bicycle paths separated from other road users stimulates the use of the bicycle (Dill 2009). The existence of a network of bicycle paths in the urban transport infrastructure is a factor encouraging residents to use the bicycle as a means of transport (Buehler, Pucher 2012; Frondel, Vance 2017) and to undertake physical activity (Parker et al. 2013). However, for bicycle users it is more important that the paths lead to specific destinations than that they cover a lengthy distance (GonzaloOrden et al. 2014). Residents also reflect upon the availability of well-organised parking spaces where bicycles can be safely left after travelling a certain distance when considering using the bicycle as a means of transport (Martens 2007).

Another direction involves analysing the perception of cycling infrastructure and decisions to use the bicycle for commuting in the context of socio-demographic features of city residents and the perception of safety (Piatkowski, Marshall 2015). Authors of studies in this field point to the fact that roads which guarantee a high level of safety encourage residents to use bicycles (Van Holle et al. 2014). The results of the said studies conducted among the lower-income population and national and ethnic minorities on the basis of wealth and the model of spending free time clearly specify the preferences of those groups and highlight the need to invest in this type of infrastructure in areas they inhabit (Lusk et al. 2017), also in order to improve road safety in those districts (Sallis et al. 2013). Lastly, not without merit is the issue of fuel price that can also urge inhabitants to choose the bicycle as a means of transport much cheaper to operate in urban areas (Frondel, Vance 2017; Stephenson et al. 2018).

A significant role in the broadly-understood promotion of cycling is played by non-governmental organisations focusing on cyclists' problems in the city, which constitutes another direction of study in this trend. Apart from their basic activity, associations are starting to formulate the urban cycling policy in a more formalised manner, e.g. by leading to the creation of special posts of "cycling officers" (Spinney 2010) or by including their representatives in planning groups preparing solutions for cyclists in a given city (Aichinger, Reinbacher 2010). As exemplified 
around the world, organisations of this kind may also be successfully co-responsible for the operation of bicycle-sharing systems (Nakamura, Abe 2014). Therefore, new elements of cycling infrastructure should not be introduced without consulting its future users. The controversial project of a bicycle lane in the Brazilian city of Curitiba, heavily criticised by cyclists, expressly indicated the need to subject the process of designing bicycle paths to civic cooperation (Duarte et al. 2014).

As in the matter of cycling safety, the benefits of daily bicycle use should become an element of the ecological education of city-dwellers. Another direction of study opens in this context: the construction of cities' cycling policies. Authorities should encourage using the bicycle as a daily means of transport by applying a number of tools regulated in strategic documents, i.e. cycling policies of individual cities (Pucher et al. 2010). However, they should take into account local preconditions (Aldred, Jungnickel 2014). The introduced cycling policies promoting the development of bicycle transport should primarily attempt to decrease car use in daily commuting (Hatfield, Boufous 2016).

\section{Urban cycling safety}

Cycling is a challenge for the safety of urban transport. In accordance with road traffic regulations in effect in numerous countries, cyclists have the same rights and obligations in traffic as other road users. As a result of insufficiently developed transport infrastructure ensuring the safety of all road users, cyclists very often find themselves in a situation where they have to share the same road with pedestrians or motor vehicles which are often large and reach much higher velocities. The issues of cyclists' safety in road traffic are one of the trends in the research on cycling in urban transport. This encompasses research on cyclists' interactions with other road users, studies describing the relationship between the state of infrastructure and cyclist behaviour and the number of accidents, and those tackling the motivations and effectiveness of safety measures in road traffic.

The first direction of study analysed in a vast array of publications refers to cyclists' interactions with other road users in the context of different infrastructural solutions, most often in relation to potential conflict situations (Silvano et al. 2016; Stipancic et al. 2016; Apasnore et al. 2017; Pokorny et al. 2018) and those resulting in accidents (Pokorny et al. 2017; Lopez et al. 2017). Research also covers the relationship between factors contributing to cyclists' collisions with vehicles and the severity of their injuries (Kim et al. 2007). It is estimated that a large-scale 'social switch' from a car to a bicycle in everyday transport may drastically increase the number of accidents and injured cyclists (Nilsson et al. 2017). The best way to limit or eliminate conflicts is to delineate limited speed zones and increase the number of bicycle paths. Such solutions are extremely beneficial to cycling safety (Schepers et al. 2017). According to the published research results (Kondo et al. 2018), when bicycle paths are constructed, especially in dangerous spots, it significantly reduces the number of road accidents and the risk of their occurrence (Pulugurtha, Thakur 2015). Cyclists are exposed to the highest risk on roads where traffic is intensive and speeds reached by drivers of other vehicles are very high. Therefore, it is important that such places receive separate cycling infrastructure in the first place (Rossetti et al. 2018). One of the crucial elements in analysing accidents involving cyclists is the search for their causes. These include: the manner of driving, especially speed, but also the state and organisation of the road infrastructure (Bíl et al. 2010), including its lighting which guarantees sufficient visibility to all traffic participants (Chen, Shen 2016). Research indicates that the speed of participating vehicles and insufficient road lighting are among the main reasons of fatal accidents (Kim et al. 2007).

A different direction of study refers to the relationship between safety and the state of cycling infrastructure and cyclists' behaviour. The published research results indicate that the bicycle path's technical state also affects the behaviour of its users and their propensity to take greater risk (Vansteenkiste et al. 2014; Vansteenkiste et al. 2017). Studies in this scope also covered the impact of the width of bicycle paths on the level of cycling safety. It was shown that broader paths are conducive to the development of hazards by allowing users to try more risky manoeuvres (Xu et al. 2016). What is also analysed here is publications regarding the impact of cyclists' behaviour on safety. Numerous papers demonstrate that 
cyclists are more cautious and reduce speed on paths shared with pedestrians; on paths delimited only for bicycles they travel at higher speeds, while observing the same level of safety (Boufous et al. 2018). Conflict between cyclists and other road users may therefore result from the organisation of infrastructure and occur depending on road width, designated direction of traffic (Methorst et al. 2017), as well as whether space is shared with pedestrians (van der Horst et al. 2014).

Together with the state and organisation of cycling infrastructure, the methods used to prevent accidents are also a pivotal factor for maintaining cycling safety. They constitute the last direction in the research trend concerned with safety (Fig. 1). A broad range of scientific papers deals with the issue of motivation and dependencies related to cyclists' use of helmets. The conducted research indicates that one's need for ensuring safety results primarily from education at home (Zavareh et al. 2018), but also from their education level (Porter et al. 2016), as factors affecting the decision to use that form of protection. The analysis of the published studies also indicates that cyclists without helmets have a greater tendency to engage in hazardous situations in traffic than helmet users (Bambach et al. 2013). As shown in the research, helmet use is also more characteristic of people using bicycles for sports and recreational purposes than of those who cycle daily at short distances (Popa et al. 2016), which again confirms the need for education in this scope. Legal regulations play a significant role in the promotion of helmets as elements of improving cyclist safety: such rules have real power to lead to increased use of this form of protection among cyclists (Kraemer 2016). Helmets may also be found in certain bicycle-sharing systems, which often results precisely from cycling regulations in force in a given region. However, research carried out in areas where systems boast such extended offer indicates that helmet use is higher among cyclists using their private bicycles (Zanotto, Winters 2017). It also compares the share of bicycle-sharing system users and private bicycle users in the number of road accidents: accident risk levels are lower for residents using shared bicycles (Fishman, Schepers 2016).

Literature studies show that cycling safety issues are of key importance and result from many factors, both infrastructural and related to the mentality and perception of safety in traffic. Therefore, the research on cyclists' safety should cover their behaviour, the state of infrastructure, the methods of implementing city policies for the expansion of cycling infrastructure, as well as actions promoting safe cycling and educating cyclists in this respect.

\section{The bicycle-sharing system as an innovation in the urban transport system}

One of the new, innovative elements of the cycling infrastructure is the bicycle-sharing system which is introduced in a growing number of cities each year. This is also reflected in research on the functioning of the bicycle in urban transport. Such a system operates on simple principles whereby bicycles are rented in self-service in different parts of the urban space, often with the help of special docking stations equipped with a customer service terminal (Midgley 2009; Shaheen et al. 2010). The intended use of shared bicycles is usually directed at offering bicycles for rent for short periods and distances. The administrators of bicycle-sharing systems reach that objective through adequately profiling the price list: a limited time of free rental encourages the quick return of the bicycle (Fishman et al. 2013; Ricci 2015). Thus, the system allows for a constant turnover of bicycles between stations and enables more users to access them.

The trend referring to the bicycle-sharing system includes studies discussing the benefits resulting from the introduction of the system in cities. They indicate that those advantages may be considered from many viewpoints, such as the economic, social or environmental. The literature query proves that economic benefits provided by the bicycle-sharing system are primarily related to the reduction of travel time, especially in large agglomerations (Bullock et al. 2017). The public bicycle, due to zero emissions and its shared nature, is perceived as one of sustainable means of urban transport (Zhang et al. 2015). Some rental companies, through liaison with other urban means of transport (e.g. buses, trams, light rail), considerably improve transport efficiency (Yang et al. 2018), chiefly in central parts of cities (Levy et al. 2017). Bicycle-sharing systems also contribute to the reduction of transport congestion 
(Hamilton, Wichman 2018) owing to their implementation into the urban multi-modal transport system (Wang, Zhou 2017). Research confirms that during the shut-down of a part of a municipal public transport network the use of the public bicycle increases (Saberi et al. 2018), which clearly shows that it may be a real alternative for the traditional forms of collective transport. Published research results prove that the very fact of placing bicycle rental stations in urban space may have a positive impact on the decision to commute to work daily using that means of transport (Cole-Hunter et al. 2015).

Another important aspect of interest to researchers is the rebalancing problem understood as external interference in the system's automated functioning model. The issue of rebalancing is a further direction of study regarding the bicycle-sharing system. The said matter is important for the system's functioning because both an empty and full docking station limits the use of this means of transport, which is coupled with rising user discouragement with the system. The problem of the shortage of bicycles and station congestion is also considered in the context of how such situations are perceived by users and how they affect the subsequent use of the system. The solution most frequently proposed by scholars is to develop an algorithm that would calculate the most time- and cost-effective system for redistributing bicycles between stations (Schuijbroek et al. 2017) depending on the number of operator's vehicles and the daily number of interventions (Bulhões et al. 2018). As shown in numerous examples, the problem may also be solved by analysing collected data regarding the scale of bicycle use in individual stations (Caggiani et al. 2018), as well as by decreasing the rental costs for users who return bicycles at less popular stations (Fricker, Gast 2016; Haider et al. 2018). A different solution may consist in implementing a system based on booking spots for returning bicycles rented in the system (Kaspi et al. 2014, 2016); such change would drastically reduce the system's unpredictability stemming from a lack of information about the station which is the user's destination. It would also allow users to more precisely determine the availability of bicycles and free space for their return at the station.

A different direction of study focuses on the factors determining the functioning of the bicycle system. There are numerous determinants which dictate whether a bicycle-sharing system succeeds or fails. Weather is a pivotal factor in determining the system's functioning: due to a number of elements, e.g. rainfall (Zhao et al. 2018) or uncomfortable air temperature, it may have an adverse impact on the number of bicycle rentals (Kim 2018). The popularity of public bicycles and the length of their use are also influenced by the number of available connections with other forms of urban transport (McBain, Caulfield 2017). It is also crucial to develop the network in order to provide access to bicycles to a growing number of users; however, not all scholars share this view (De Chardon et al. 2017), indicating a lack of relationship between the popularity of the bicycle system and the number of stations.

Researchers' attention is also directed at the method of funding the system, which constitutes another direction of study within this trend. In most cases, local governments are responsible for the introduction and maintenance of public bicycles in cities. The words 'municipal' or 'public' included in the names of systems (in Poland) refer to the main source of funding by indicating who is responsible for the system. Another method is to co-finance the systems through advertising companies, which helps the city reach a lower cost of servicing the system in return for an opportunity to earn on advertising space. Advertising companies Jcdecaux and Clear Channel as well as Barclays have played a pivotal role in the development of bicycle-sharing systems in Europe - motivated by profit they have substantially popularised this form of transport (Parkes et al. 2013). Shared bicycles and bicycle stations are attractive for advertisements: the stations are visible and numerous in the city space, and the constantly moving bicycles allow the advertisement to reach a wide range of customers (Schoner et al. 2012). In this case, however, it is worth bearing in mind the potential risk of a decrease in the quality of bicycle rental service for the benefit of the advertising function (DeMaio 2009). Alongside the total income from bicycle rentals and the inflows from advertisements and local government subsidies, the sponsoring mod$\mathrm{el}$ is one of the sources of funding bicycle-sharing systems (Midgley 2011). It constitutes a significant subsidy for the development of the urban bicycle system and at the same time it encourages 
customers and stakeholders of the sponsor to switch from a car to a bicycle (Cohen, Kietzmann 2014). The said model takes many forms: it may consist in supporting the whole system of particular stations (Parkes et al. 2013).

It is worth noting that bicycle systems are being established in a growing number of cities, becoming a new alternative for the traditional forms of public transport, i.e. bus, tram, rail and others. Each subsequent generation of the bicycle-sharing system creates new possibilities and provides new challenges for researchers. The literature study conducted by the author allowed for an indication of several directions of study related to the bicycle-sharing system (Fig. 1), each of which provides opportunities to conduct more in-depth research. In the light of the intensive development of bicycle transport, one may assert that the immediate future will see a rise of new, additional directions of study important for the representatives of geographic, social, technical and economic sciences.

\section{Summary}

Literature studies regarding the socio-economic aspects of cycling in cities indicate that there is a number of problems both in city space and in the perception of cycling by city residents. The analysed publications show that infrastructural aspects intermingle with social issues and affect each other. The conducted literature query resulted in the distinguishing of the most important research trends related to cycling in urban transport, and subsequently, individual directions of study within each trend. Numerous publications tackling the issue of safety, the perception of the bicycle as a means of transport and the bicycle-sharing system point to the significance of those topics for cycling in urban transport. The most numerous group of analysed publications comprises papers describing the functioning of the bicycle-sharing system, which directly arises from its innovativeness. It is necessary to mention the insufficient number of regional studies referring to the operation of systems on a larger-than-local scale. In this context, the establishment of regional bicycle-sharing systems may direct research to larger areas than currently covered.
When analysing the results of studies to date regarding the functioning of bicycle-sharing systems, the author observed a problem with collecting reliable data describing certain phenomena. The studies of the described problems are commonly conducted using statistical data collected by system operators and data shared in the operators' on-line services. Thus obtained information may be used as a guide for the planning of bicycle path networks by reconstructing the most popular routes cyclists take (Bao et al. 2017). Qualitative research also plays a significant role in the assessment of the systems' functioning; it includes interviews conducted with potential system users but also people who shape the cycling policy of cities. Of real value are survey studies determining the most frequent destinations of system users and obtaining the latter's opinions on the functioning of the system. The combination of all pieces of information thus obtained constitutes a comprehensive approach to the issue and provides an opportunity to create a reliable description of the analysed phenomena.

One of the conclusions of the literature study is that the perception of the bicycle as a means of transport plays a key role. The manner in which city residents perceive cycle commuting is a significant challenge due to a number of factors which encourage or limit the use of the bicycle in the city. On the one hand, numerous scientific publications present the benefits of cycling in cities as having a positive effect not only on the budget and health of the resident, but also on the environment and the city economy. On the other hand, they enumerate a wide range of problems faced by and restraints imposed on cycling which will probably continue to be studied by scholars from different scientific fields. The publications assert that the bicycle-sharing system is an innovative element of the urban transport system. A concept which combines many advantages for cities and the residents is also full of limitations and problems related to the functioning of the system in spatial, social, economic and technological contexts. The problem of rebalancing bicycle systems and limits on their use described in the said publications may be a considerable barrier to their development in urban areas. Therefore, the results of the literature query may be of great importance in practice by depicting solutions that may help overcome these problems. The growing 
popularity of sustainable solutions in urban transport and the innovative nature of the bicycle-sharing system cause new technological solutions in this scope to emerge each year. It should be expected that the development of this form of transport will contribute to new studies dealing with its application and to cognitive studies, as well as theoretical and methodological ones.

\section{References}

Aichinger W., Reinbacher E., 2010. Cycling policy and practice in mega-cities Rio de Janeiro and Cairo: A case study. Proceedings SB10 Amman: Sustainable Architecture and Urban Development (held on 12-14 July 2010 in Amman, Jordan) II: 361-376.

Aldred R., Jungnickel K., 2014. Why culture matters for transport policy: The case of cycling in the UK. Journal of Transport Geography 34: 78-87. DOI: 10.1016/j. jtrangeo.2013.11.004

Apasnore P., Ismail K., Kassim A., 2017. Bicycle-vehicle interactions at mid-sections of mixed traffic streets: Examining passing distance and bicycle comfort perception. Accident Analysis \& Prevention 106: 141-148. DOI: 10.1016/j.aap.2017.05.003

Bambach M.R., Mitchell R.J., Grzebieta R.H., Olivier J., 2013. The effectiveness of helmets in bicycle collisions with motor vehicles: A case-control study. Accident Analysis $\mathcal{E}$ Prevention 53: 78-88. DOI: 10.1016/j.aap.2013.01.005

Bao J., He T., Ruan S., Li Y., Zheng Y., 2017. Planning bike lanes based on sharing-bikes' trajectories. KDD '17 Proceedings of the $23^{\text {rd }}$ ACM SIGKDD International Conference on Knowledge Discovery and Data Mining: 1377-1386. DOI: 10.1145/3097983.3098056

Bharadwaj S., Ballare S., Rohit, Chandel M.K., 2017. Impact of congestion on greenhouse gas emissions for road transport in Mumbai metropolitan region. Transportation Research Procedia 25: 3538-3551. DOI: 10.1016/j.trpro.2017.05.282

Bíl M., Bílová M., Müller I., 2010. Critical factors in fatal collisions of adult cyclists with automobiles. Accident Analysis \& Prevention 42(6): 1632-1636. DOI: 10.1016/j. aap.2010.04.001

Boufous S., Hatfield J., Grzebieta R., 2018. The impact of environmental factors on cycling speed on shared paths. Accident Analysis \& Prevention 110: 171-176. DOI: $10.1016 / \mathrm{j}$. aap.2017.09.017

Buehler R., Pucher J., 2012. Cycling to work in 90 large American cities: New evidence on the role of bike paths and lanes. Transportation 39(2): 40 - 432. DOI: 10.1007/s11116011-9355-8

Bulhões T., Subramanian A., Erdoğan G., Laporte G., 2018. The static bike relocation problem with multiple vehicles and visits. European Journal of Operational Research 264(2): 508-523. DOI: 10.1016/j.ejor.2017.06.028

Bullock C., Brereton F., Bailey S., 2017. The economic contribution of public bike-share to the sustainability and efficient functioning of cities. Sustainable Cities and Society 28: 76-87. DOI: 10.1016/j.scs.2016.08.024

Caggiani L., Camporeale R., Marinelli M., Ottomanelli M., 2018. User satisfaction based model for resource alloca- tion in bike-sharing systems. Transport Policy (in press, corrected proof). DOI: 10.1016/j.tranpol.2018.03.003

Chen P., Shen Q., 2016. Built environment effects on cyclist injury severity in automobile-involved bicycle crashes. Accident Analysis \& Prevention 86: 239-246. DOI: 10.1016/j.aap.2015.11.002

Cohen B., Kietzmann J., 2014. Ride on! Mobility business models for the sharing economy. Organization $\mathcal{E}$ Environment 27(3): 279-296. DOI: 10.1177/1086026614546199

Cole-Hunter T., Donaire-Gonzalez D., Curto A., Ambros A., Valentin A., Garcia-Aymerich J., Martinez D., Braun L.M., Mendez M., Jerrett M., Rodriguez D., de Nazelle A., Nieuwenhuijsen M., 2015. Objective correlates and determinants of bicycle commuting propensity in an urban environment. Transportation Research Part D: Transport and Environment 40: 132-143. DOI: 10.1016/j.trd.2015.07.004

De Chardon C.M., Caruso G., Thomas I., 2017. Bicycle sharing system 'success' determinants. Transportation Research Part A: Policy and Practice 100: 202-214. DOI: 10.1016/j. tra.2017.04.020

DeMaio P., 2009. Bike-sharing: History, impacts, models of provision, and future. Journal of Public Transportation 12(4): 41-56. DOI: http://dx.doi.org/10.5038/23750901.12.4.3

Dill J., 2009. Bicycling for transportation and health: The role of infrastructure. Journal of Public Health Policy 30(1): Connecting active living research to policy solutions: S95-S110. Retrieved from http://www.jstor.org/stable/40207254 (accessed: 8 April 2018)

Duarte F., Procopiuck M., Fujioka K., 2014. ‘No bicycle lanes!' Shouted the cyclists. A controversial bicycle project in Curitiba, Brazil. Transport Policy 32: 180-185. DOI: 10.1016/j.tranpol.2014.01.010

Fishman E., Schepers P., 2016. Global bike share: What the data tells us about road safety. Journal of Safety Research 56: 41-45. DOI: 10.1016/j.jsr.2015.11.007

Fishman E., Washington S., Haworth N.L., 2013. Bike share: A synthesis of literature. Transport Reviews 33(2): 148-165. DOI: 10.1080/01441647.2013.775612

Fricker C., Gast N., 2016. Incentives and redistribution in homogeneous bike-sharing systems with stations of finite capacity. Euro Journal on Transportation and Logistics 5(3): 261-291.

Frondel M., Vance C., 2017. Cycling on the extensive and intensive margin: The role of paths and prices. Transportation Research Part A: Policy and Practice 104: 21-31. DOI: 10.1016/j.tra.2017.06.018

Gatersleben B., Appleton K.M., 2007. Contemplating cycling to work: Attitudes and perceptions in different stages of change. Transportation Research Part A: Policy and Practice 41(4): 302-312. DOI: 10.1016/j.tra.2006.09.002

Gonzalo-Orden H., Linares A., Velasco L., Diez J.M., Rojo M., 2014. Bikeways and cycling urban mobility. Procedia - Social and Behavioral Sciences 160: 567-576. DOI: 10.1016/j. sbspro.2014.12.170

Gössling S., Choi A.S., 2015. Transport transitions in Copenhagen: Comparing the cost of cars and bicycles. Ecological Economics 113: 106-113. DOI: 10.1016/j. ecolecon.2015.03.006

Haider Z., Nikolaev A., Kang J.E., Kwon C., 2018. Inventory rebalancing through pricing in public bike sharing systems. European Journal of Operational Research (in press, accepted manuscript). DOI: 10.1016/j.ejor.2018.02.053

Hatfield J., Boufous S., 2016. The effect of non-recreational transport cycling use of other transport modes: A 
cross-sectional on-line survey. Transportation Research Part A: Policy and Practice 92: 220-231. DOI: 10.1016/j. tra.2016.08.011

Hamilton T., Wichman C.J., 2018. Bicycle infrastructure and traffic congestion: Evidence from DC's Capital Bikeshare'. Journal of Environmental Economics and Management 87: 72-93. DOI: 10.1016/j.jeem.2017.03.007

Heesch K.C., Giles-Corti B., Turrell G., 2015. Cycling for transport and recreation: Associations with the socio-economic, natural and built environment. Health $\mathcal{E}$ Place 36: 152-161. DOI: 10.1016/j.healthplace.2015.10.004

Jennings G., 2015: Finding our balance: Considering the opportunities for public bicycle systems in Cape Town, South Africa. Research in Transportation Business \& Management 15: 6-14. DOI: 10.1016/j.rtbm.2014.09.001

Kaspi M., Raviv T., Tzur M., 2014. Parking reservation policies in one-way vehicle sharing systems. Transportation Research Part B: Methodological 62: 35-50. DOI: 10.1016/j. trb.2014.01.006

Kaspi M., Raviv T., Tzur M., Galili H., 2016. Regulating vehicle sharing systems through parking reservation policies: Analysis and performance bounds. European Journal of Operational Research 251(3): 969-987. DOI: 10.1016/j. ejor.2015.12.015

Kondo M.C., Morrison C., Guerra E., Kaufman E.J., Wiebe D.J., 2018. Where do bike lanes work best? A Bayesian spatial model of bicycle lanes and bicycle crashes. Safety Science 103: 225-233. DOI: 10.1016/j.ssci.2017.12.002

Kim J.K., Kim S., Ulfarsson G.F., Portello L.A., 2007. Bicyclist injury severities in bicycle-motor vehicle accidents. Accident Analysis \& Prevention 39(2): 238-251. DOI: 10.1016/j. aap.2006.07.002

Kim K., 2018. Investigation on the effects of weather and calendar events on bike-sharing according to the trip patterns of bike rentals of stations. Journal of Transport Geography 66: 309-320. DOI: 10.1016/j.jtrangeo.2018.01.001

Kraemer J.D., 2016. Helmet laws, helmet use, and bicycle ridership. Journal of Adolescent Health 59(3): 338-344. DOI: 10.1016/j.jadohealth.2016.03.009

Levy N., Golani C., Ben-Elia E., 2017. An explanatory study of spatial patterns of cycling in Tel Aviv using passively generated bike-sharing data. Journal of Transport Geography (in press, corrected proof). DOI: 10.1016/j. jtrangeo.2017.10.005

Lopez D., Glickman M.E., Soumerai S.B., Hemenway D., 2017. Identifying factors related to a hit-and-run after a vehicle-bicycle collision. Journal of Transport $\mathcal{E}$ Health (in press, corrected proof). DOI: 10.1016/j.jth.2017.10.005

Lusk A.C., Anastasio A., Shaffer N., Wu J., Li Y., 2017. Biking practices and preferences in a lower income, primarily minority neighborhood: Learning what residents want. Preventive Medicine Reports 7: 232-238. DOI: 10.1016/j. pmedr.2017.01.006

Martens K., 2007. Promoting bike-and-ride: The Dutch experience. Transportation Research Part A 41: 326-338. DOI: 10.1016/j.tra.2006.09.010

McBain C., Caulfield B., 2017. An analysis of the factors influencing journey time variation in the Cork Public Bike System. Sustainable Cities and Society (in press, corrected proof). DOI: 10.1016/j.scs.2017.09.030

Midgley P., 2009. The role of smart bike-sharing systems in urban mobility. Journeys 2(2): 23-31.

Midgley P., 2011. Bicycle-sharing schemes: Enhancing sustainable mobility in urban areas. Commission On Sustain- able Development, Nineteenth Session New York, 2-13 May 2011. Background Paper No. 8. CSD19/2011/BP8.

Methorst R., Schepers P., Kamminga J., Zeegers T., Fishman E., 2017. Can cycling safety be improved by opening all unidirectional cycle paths for cycle traffic in both directions? A theoretical examination of available literature and data. Accident Analysis and Prevention 105: 38-43. DOI: 10.1016/j.aap.2016.05.018

Nakamura H., Abe N., 2014. The role of a non-profit organisation-run public bicycle-sharing programme: The case of Kitakyushu City, Japan. Journal of Transport Geography 41: 338-345. DOI: 10.1016/j.jtrangeo.2013.11.009

Nilsson P., Stigson H., Ohlin M., Standorth J., 2017. Modelling the effect on injuries and fatalities when changing mode of transport form from car to bicycle. Accident Analysis $\mathcal{E}$ Prevention 100: 30-36. DOI: 10.1016/j.aap.2016.12.020

Oja P., Vuori I., Paronen O., 1998. Daily walking and cycling to work: Their utility as health-enhancing physical activity. Patient Education and Counseling 33(1): S87-S94. DOI: 10.1016/S0738-3991(98)00013-5

Parker K.M., Rice J., Gustat J., Ruley J., Spriggs A., Johnson C., 2013. Effect of bike lane infrastructure improvements on ridership in one New Orleans neighborhood. Annals of Behavioral Medicine 45(1): 101-107. DOI: 10.1007/ s12160-012-9440-z

Parkes S.D., Marsden G., Shaheen S.A., Cohen A.P., 2013. Understanding the diffusion of public bikesharing systems: Evidence from Europe and North America. Journal of Transport Geography 31: 94-103. DOI: 10.1016/j. jtrangeo.2013.06.003

Piatkowski D.P., Marshall W.E., 2015. Not all prospective bicyclists are created equal: The role of attitudes, socio-demographics, and the built environment in bicycle commuting. Travel Behavior and Society 2(3): 166-173. DOI: 10.1016/j.tbs.2015.02.001

Pokorny P., Pritchard R., Pitera K., 2018. Conflicts between bikes and trucks in urban areas - A survey of Norwegian cyclists. Case Studies on Transport Policy 6(1): 147-155. DOI: $10.1016 /$ j.cstp.2017.11.010

Pokorny P., Drescher J., Pitera K., Jonsson T., 2017. Accidents between freight vehicles and bicycles, with a focus on urban areas. Transportation Research Procedia 25: 999-1007. DOI: $10.1016 /$ j.trpro.2017.05.474

Popa I., Ferraro O.E., Orsi C., Morandi A., Montomoli C., 2017. Bicycle helmet use patterns in Italy. A description and analysis of survey data from an Italian friends of cycling association. Accident Analysis \& Prevention 108: 268-274. DOI: 10.1016/j.aap.2017.09.003

Porter A.K., Salvo D., Kohl Iii H.W., 2016. Correlates of helmet use among recreation and transportation bicyclists. American Journal of Preventive Medicine 51(6): 999-1006. DOI: $10.1016 /$ j.amepre.2016.08.033

Pucher J., Dill J., Handy S., 2010. Infrastructure, programs, and policies to increase bicycling: An international review. Preventive Medicine 50(suppl.): 106-125. DOI: 10.1016/j.ypmed.2009.07.028

Pulugurtha S.S., Thakur V., 2015. Evaluating the effectiveness of on-street bicycle lane and assessing risk to bicyclists in Charlotte, North Carolina. Accident Analysis $\mathcal{E}$ Prevention 76: 34-41. DOI: 10.1016/j.aap.2014.12.020

Ricci M., 2015. Bike sharing: A review of evidence on impacts and processes of implementation and operation. Research in Transportation Business \& Management 15: 28-38. DOI: 10.1016/j.rtbm.2015.03.003 
Rodrigue J.P., Comtois C., Slack B., 2013. The geography of transport systems (third edition). Routledge.

Rossetti T., Guevara C.A., Galilea P., Hurtubia R., 2018. Modeling safety as a perceptual latent variable to assess cycling infrastructure. Transportation Research Part A: Policy and Practice 111: 252-265. DOI: 10.1016/j.tra.2018.03.019

Saberi M., Ghamami M., Gu Y., Shojaei M.H., Fishman E., 2018. Understanding the impacts of a public transit disruption on bicycle sharing mobility patterns: A case of tube strike in London. Journal of Transport Geography 66: 154-166. DOI: 10.1016/j.jtrangeo.2017.11.018

Sallis J.F., Conway T.L., Dillon L.I., Frank L.D., Adams M.A., Cain K.L., Saelens B.E., 2013. Environmental and demographic correlates of bicycling. Preventive Medicine 57(5): 456-460. DOI: 10.1016/j.ypmed.2013.06.014

Schepers P., Fishman E., Beelen R., Heinen E., Wijnen W., Parkin J., 2015. The mortality impact of bicycle paths and lanes related to physical activity, air pollution exposure and road safety. Journal of Transport $\mathcal{E}$ Health 2(4): 460 473. DOI: $10.1016 /$ j.jth.2015.09.004

Schepers P., Twisk D., Fishman E., Fyhri A., Jensen A., 2017. The Dutch road to a high level of cycling safety. Safety Science 92: 264-273. DOI: 10.1016/j.ssci.2015.06.005

Schoner J.E., Harrison A., Wang X., 2012. Sharing to grow: Economic activity associated with nice ride bike share stations. Hubert H. Humphrey School of Public Affairs, University of Minnesota.

Schuijbroek J., Hampshire R.C., van Hoeve W.-J., 2017. Inventory rebalancing and vehicle routing in bike sharing systems. European Journal Of Operational Research 257(3): 992-1004. DOI: 10.1016/j.ejor.2016.08.029

Shaheen S., Guzman S., Zhang H., 2010. Bikesharing in Europe, the Americas, and Asia: Past, present, and future. Transportation Research Record 2143: 159-167.

Silvano A.P., Koutsopoulos H.N., Ma X., 2016. Analysis of vehicle-bicycle interactions at unsignalized crossings. A probabilistic approach and application. Accident Analysis E Prevention 97: 38-48. DOI: 10.1016/j.aap.2016.08.016

Spinney J., 2010. Mobilising sustainability: Partnership working between a pro-cycling NGO and local government in London (UK). In: Peters M., Fudge S., Jackson $\mathrm{T}$. (eds), Low carbon communities imaginative approaches to combating climate change locally. Edward Elgar Publishing Ltd, Cheltenham: 89-107.

Stephenson J., Spector S., Hopkins D., McCarthy A., 2018. Deep interventions for a sustainable transport future. Transportation Research Part D: Transport and Environment 61(B): 356-372. DOI: 10.1016/j.trd.2017.06.031

Stipancic J., Zangenehpour S., Miranda-Moreno L., Saunier N., Granie M.A., 2016. Investigating the gender differences on bicycle-vehicle conflicts at urban intersections using an ordered logit methodology. Accident Analysis $\mathcal{E}$ Prevention 97: 19-27. DOI: 10.1016/j.aap.2016.07.033

van der Horst A.R.A., de Goede M., de Hair-Buijssen S., Methorst R., 2014. Traffic conflicts on bicycle paths: A systematic observation of behaviour from video. Accident Analysis \& Prevention 62: 358-368. DOI: 10.1016/j. aap.2013.04.005
Van Holle V., Van Cauwenberg J., Deforche B., Goubert L., Maes L., Nasar J., Van de Weghe N., Salmon J., De Bourdeaudhuij I., 2014. Environmental invitingness for transport-related cycling in middle-aged adults: A proof of concept study using photographs. Transportation Research Part A: Policy and Practice 69: 432-446. DOI: 10.1016/j. tra.2014.09.009

Vansteenkiste P., Zeuwts L., Cardon G., Philippaerts R., Lenoir M., 2014. The implications of low quality bicycle paths on gaze behavior of cyclists: A field test. Transportation Research Part F: Traffic Psychology and Behaviour 23: 81-87. DOI: 10.1016/j.trf.2013.12.019

Vansteenkiste P., Zeuwts L., van Maarseveen M., Cardon G., Savelsbergh G., Lenoir M., 2017. The implications of low quality bicycle paths on the gaze behavior of young learner cyclists. Transportation Research Part F: Traffic Psychology and Behaviour 48: 52-60. DOI: 10.1016/j.trf.2017.04.013

Wang M., Zhou X., 2017. Bike-sharing systems and congestion: Evidence from US cities. Journal of Transport Geography 65: 147-154. DOI: 10.1016/j.jtrangeo.2017.10.022

Wardman M., Tight M., Page M., 2007. Factors influencing the propensity to cycle to work. Transportation Research Part A: Policy and Practice 41(4): 339-350. DOI: 10.1016/j. tra.2006.09.011

Xu C., Yang Y., Jin S., Qu Z., Hou L., 2016. Potential risk and its influencing factors for separated bicycle paths. Accident Analysis \& Prevention 87: 59-67. DOI: 10.1016/j. aap.2015.11.014

Yang X., Cheng Z., Chen G., Wang L., Ruan Z., Zheng Y., 2018. The impact of a public bicycle-sharing system on urban public transport networks. Transportation Research Part A: Policy and Practice 107: 246-256. DOI: 10.1016/j. tra.2017.10.017

Zanotto M., Winters M.L., 2017. Helmet use among personal bicycle riders and bike share users in Vancouver, BC. American Journal of Preventive Medicine 53(4): 465-472. DOI: 10.1016/j.amepre.2017.04.013

Zavareh M.F., Hezaveh A.M., Nordfjaern T., 2018. Intention to use bicycle helmet as explained by the health belief model, comparative optimism and risk perception in an Iranian sample. Transportation Research Part F: Traffic Psychology and Behaviour 54: 248-263. DOI: 10.1016/j. trf.2018.02.003

Zawieska J., Pieriegud J., 2018. Smart city as a tool for sustainable mobility and transport decarbonization. Transport Policy 63: 39-50. DOI: 10.1016/j.tranpol.2017.11.004

Zhang L., Zhang J., Duan Z., Bryde D., 2015. Sustainable bike-sharing systems: Characteristics and commonalities across cases in urban China. Journal of Cleaner Production 97: 124-133. DOI: 10.1016/j.jclepro.2014.04.006

Zhao J., Wang J., Xing Z., Luan X., Jiang Y., 2018. Weather and cycling: Mining big data to have an in-depth understanding of the association of weather variability with cycling on an off-road trail and an on-road bike lane. Transportation Research Part A: Policy and Practice 111: 119-135. DOI: 10.1016/j.tra.2018.03.001 